\title{
Severe Arterial Hypertension in Adults: When to Think of Aortic Coarctation
}

\author{
Elouardighi Kaoutar ${ }^{*}$, Dinia Mohamed
}

Cardiovascular Department, IBN SINA University Hospital, Rabat, Morocco

DOI: $10.36347 /$ sjmcr.2020.v08i04.009

| Received: 19.03.2020 | Accepted: 27.03.2020 | Published: 08.04.2020

*Corresponding author: Elouardighi Kaoutar

Abstract

Case Report

Coarctation of the aorta is a congenital narrowing of the aorta, located just below the emergence of the left subclavian artery. It is often discovered at birth, but can be later diagnosed when dealing with a resistant arterial hypertension. We report the case of a 45-year-old male admitted to the emergency department for a hypertension emergency, in whom the diagnostic work up found an aortic coarctation. A percutaneous treatment made it possible to control the arterial hypertension.

Keywords: Coarctation of the aorta, Hypertension, A percutaneous treatment.

Copyright @ 2020: This is an open-access article distributed under the terms of the Creative Commons Attribution license which permits unrestricted use, distribution, and reproduction in any medium for non-commercial use (NonCommercial, or CC-BY-NC) provided the original author and source are credited.

\section{INTRODUCTION}

Coarctation of the aorta is a common birth defect ( 5 to $8 \%$ of congenital heart disease). It is an aortic stenosis located preferentially at the level of the isthmus below the emergence of the left subclavian artery. Aortic coarctation is usually diagnosed during infancy, but can go undiagnosed until old age and only present as hypertension if the clinical signs are overlooked.

\section{Case Report}

We report the case of a 45-year-old male with history of cataract surgery on both eyes, under medical therapy for high blood pressure for 12 years. His blood pressure levels were uncontrolled under amlodipine, valsartan and hydrochlorothiazide. He was admitted to the emergency department for recent occipital headache, which was resistant to the usual analgesic treatments. The patient also complained from dizziness, tinnitus and visual fog. Physical examination found high blood pressure of 220/110 $\mathrm{mmHg}$ in both arms and the auscultation revealed a $5 / 6$ systolic murmur at the left border of the sternum. Femoral pulses were slightly decreased and the rest of the clinical examination was unremarkable.

The electrocardiogram showed a sinus rhythm at 78 beat per minute, a left ventricular hypertrophy and no axis displacement or repolarization anomaly. Chest radiography showed an erosion of the lower edge of the ribs. We carried out a complete work up to search for a resistant hypertension etiology. Transthoracic echocardiography showed concentric left ventricular hypertrophy with good systolic function, dilated left atrium and an ascending aorta of normal dimensions. Computed tomography angiography (CTA) revealed a short stenosis at the level of the aortic isthmus with thoracic and epigastric collateral circulation (figure 1).

The patient underwent percutaneous angioplasty with stent implantation at the level of the coarctation. After a 10 months follow-up, blood pressure is controlled at $130 / 80 \mathrm{mmHg}$ under antihypertensive monotherapy. 


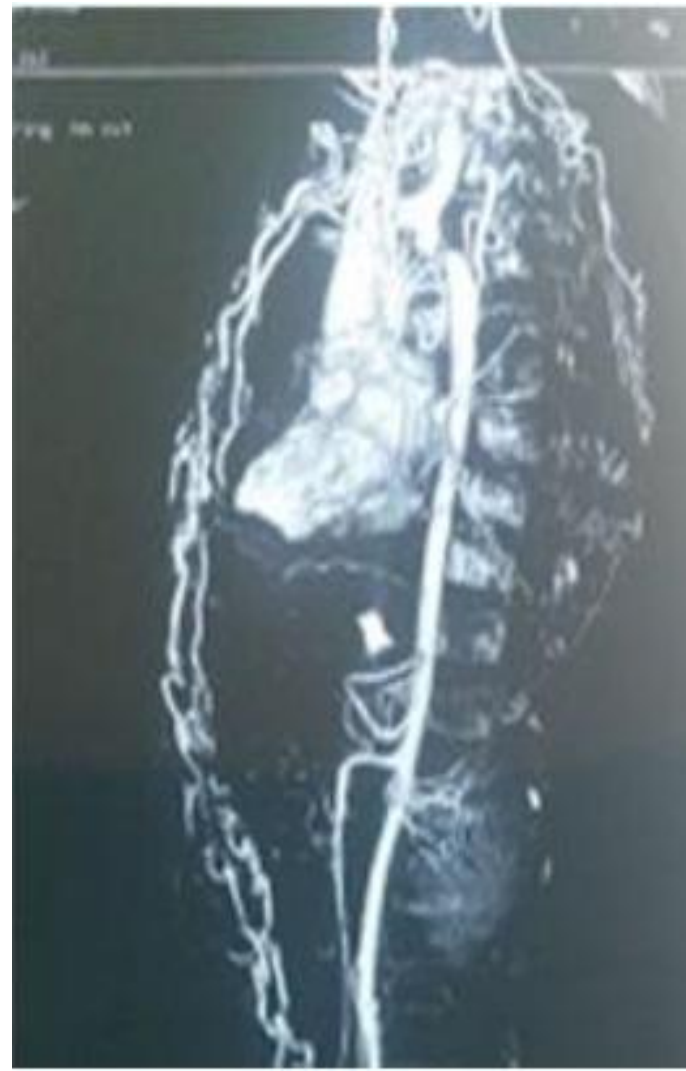

Figure 1: CTA showing aortic coarcation

\section{DiscUSSION}

Coarctation of the aorta is a congenital narrowing of the aorta, located just below the emergence of the left subclavian artery, marking the beginning of the descending thoracic aorta. It is considered simple when alone, and complex in the presence of associated anomalies such as a congenital heart disease (bicuspid aortic valve, sub-aortic stenosis ...), an aneurysm of the Willis polygon or a retroesophageal subclavian artery.

This pathology is often discovered at birth by systematic palpation of the femoral pulses, but can be later diagnosed in older children or even adults in the case of high blood pressure in $10-15 \%$ of cases. Unoperated patients generally die before the age of 50 due to high blood pressure complications, early coronary artery disease and aneurysm formation below or above the coarctation [1-3].

High blood pressure is the most common telltale sign. There is a blood pressure gradient between the upper and lower limbs that can be attenuated by the presence of a collateral circulation. Pulse at the lower limbs is decreased or absent. An ejection systolic murmur may be heard best at the left or right upper sternal borders, but is usually heard best over the back in the left interscapular region. CTA or magnetic resonance angiography should be carried out first. They make the diagnosis and describe the exact location, diameter and length of the narrowed segment.
According to guidelines, only coarctations responsible for a pressure gradient greater than 20 $\mathrm{mmHg}$ at rest and $40 \mathrm{mmHg}$ at exercise should be treated [4]. Two options are available, surgery or endovascular treatment by angioplasty. The choice of intervention should be determined by a multidisciplinary team experienced in treating patients with congenital heart disease and is dependent on the underlying morphology, age of the patient, and the presence or absence of other cardiac lesions [4-6]. Recoarctations and aneurysms are the main postoperative complications. In addition, the risk of persistent hypertension increases with age and reaches $40 \%$ beyond 40 years $[7,8]$. The long-term survival rate of patients operated at an adult age is significantly lower than that of the normal population $[9,10]$.

\section{CONCLUSION}

Coarctation of the aorta should be considered in the case of hypertension of the young subject associated with a decreased femoral pulse. Early diagnosis helps prevent the risk of persistent hypertension, reduces the long-term morbidity and improves survival.

\section{REFERENCES}

1. Wells WJ, Prendergast TW, Berdjis F, Brandl D, Lange PE, Hetzer R, Starnes VA. Repair of coarctation of the aorta in adults: the fate of systolic hypertension. The Annals of thoracic surgery. 1996 Apr 1;61(4):1168-71.

2. Aris A, Subirana MT, Ferrés P, Torner-Soler M. Repair of aortic coarctation in patients more than 50 years of age. The Annals of thoracic surgery. 1999 May 1;67(5):1376-9.

3. Artigou J, Monsuez J. Coarctation de l'aorte et interruption de l'arche aortique. In : Cardiologie et maladies vasculaires. Ed. Masson. 2007 ; 945-48.

4. Warnes CA, Williams RG, Bashore TM, Child JS, Connolly HM, Dearani JA, del Nido P, Fasules JW, Graham TP, Hijazi ZM, Hunt SA. ACC/AHA 2008 guidelines for the management of adults with congenital heart disease: a report of the American college of cardiology/American heart association task force on practice guidelines (writing committee to develop guidelines on the management of adults with congenital heart disease) developed in collaboration with the american society of echocardiography, heart rhythm society, international society for adult congenital heart disease, society for cardiovascular angiography and interventions, and .... Journal of the American College of Cardiology. 2008 Dec 2;52(23):e143-263.

5. Feltes TF, Bacha E, Beekman III RH, Cheatham JP, Feinstein JA, Gomes AS, Hijazi ZM, Ing FF, De Moor M, Morrow WR, Mullins CE. Indications for cardiac catheterization and intervention in pediatric cardiac disease: a scientific statement 
from the American Heart Association. Circulation. 2011 Jun 7;123(22):2607-52.

6. Silversides CK, Kiess M, Beauchesne L, Bradley T, Connelly M, Niwa K, Mulder B, Webb G, Colman J, Therrien J. Canadian Cardiovascular Society 2009 Consensus Conference on the management of adults with congenital heart disease: outflow tract obstruction, coarctation of the aorta, tetralogy of Fallot, Ebstein anomaly and Marfan's syndrome. Canadian Journal of Cardiology. 2010 Mar 1;26(3):e80-97.

7. Liberthson RR, Pennington DG, Jacobs ML, Daggett WM. Coarctation of the aorta: review of 234 patients and clarification of management problems. The American journal of cardiology. 1979 Apr 1;43(4):835-40.
8. Werning C, SCHÖNBECK MA, Weidmann P, Baumann K, Gysling E, Wirz P, Siegenthaler W. Plasma Renin Activity in Patients with Coarctation of the Aorta: A Comment on the Pathogenesis of Prestenotic Hypertension. Circulation. 1969 Nov;40(5):731-7.

9. Cohen MA, Fuster V, Steele PM, Driscoll D, McGoon DC. Coarctation of the aorta. Long-term follow-up and prediction of outcome after surgical correction. Circulation. 1989 Oct;80(4):840-5.

10. Presbitero P, Demarie D, Villani M, Perinetto EA, Riva G, Orzan F, Bobbio M, Morea M, Brusca A. Long term results (15-30 years) of surgical repair of aortic coarctation. Heart. 1987 May 1;57(5):4627. 